\title{
New Method to Study The Effect of Stacking Sequence on Composite Single-Lap Joint Strength
}

\author{
Jingwei XIANG ${ }^{1, a}$, Zhidong GUAN ${ }^{1, b, *}$ and Zengshan LI $^{1, c}$ \\ ${ }^{1}$ School of Aeronautical Science and Engineering, Beihang University, Beijing 100191, China \\ a stanakin@sina.com, ${ }^{\mathrm{b}}$ zdguan@buaa.edu.cn, ${ }^{\mathrm{c}}$ lzshan83@163.com \\ *corresponding author
}

Keywords: composite, stacking sequence, single-lap

\begin{abstract}
The ply stacking sequence of Carbon Fiber Reinforced Plastic (CFRP) has influence on failure strength of bonded joints made by this CFRP substrates. Existing researches have demonstrated that the specific influencing mechanism is related to the position of 0 ply inside the substrates. Tension load of such joints normally keeps increasing until delamination between $0^{\circ}$ ply and its neighboring plies happens, and the position of $0^{\circ}$ ply determines whether it delaminates easily or not. This mechanism takes effect in both local and global ways. Laminates with $0^{\circ}$ plies further from the adhesive interface are found to be more resistant against tension loading because this configuration makes the local crack propagation more complex. On the other hand, $0^{\circ}$ plies being the surface layer of laminates brings higher bending stiffness globally, reducing intralaminar peel stress caused by eccentric loading of single lap joint, thus increase joint strength. In the case of quasi-isotropic symmetric laminates, the local and global factors are working oppositely and coupling with each other. A bonded joint made with two composite substrates of different stacking sequence can eliminate this coupling effect and draw reliable conclusion
\end{abstract}

\section{Introduction}

Adhesively bonded composite joints are widely used in modern aeronautical industry. In academic researches, single lap joints are the most commonly used type of bonded joints. One factor that has influence on failure mode and strength of single lap joints is the stacking sequence of composite laminates.

The initial research of stacking sequence began in the middle of 1970s. Renton and Vinson ${ }^{[1]}$ made bonded joints using glass fiber reinforced epoxy resin. The laminates are all $0^{\circ}$ unidirectional or $45 / 0 / 45 / 0$. The joint strength is found to be slightly influenced by ply orientation at the adhesively bonding interface.

Further investigation was made by Matthews and Tester ${ }^{[2]}$ in 1985 . They composed symmetric laminates by altering proportions of $0^{\circ}$ and $\pm 45^{\circ}$ plies and found that higher joint strength comes with higher proportion of $0^{\circ}$ plies, the strength being maximum when all layers are $0^{\circ}$. In the case of 8-ply symmetric laminates, joint strength are the highest when $0^{\circ}$ plies are located at the laminate surface, and the lowest when $0^{\circ}$ plies are in the middle.

In 1993 Kairouz and Matthews ${ }^{[3]}$ studied orthotropic laminates composed of $0^{\circ}$ and $90^{\circ}$ by experiments and finite element method. They found that cracking initiation happens at the surface ply near the end of bonding area. If the surface ply is $0^{\circ}$, the crack would propagate along the longitudinal direction inside this surface play. If it is $90^{\circ}$, transverse failure firstly occurs in this ply, then delamination happens and grows between 90/0 interface until final failure of whole structure.

In 2013 Purimpat and Jerome et al. ${ }^{[5]}$ brought up new viewpoint with respect to the relationship between stacking sequence and joint strength. They created the concept of local and global effects. By composing QIQH (composing quasi-isotropic quasi-homogenous) laminates, they excluded global effect and concluded that joint strength increases as $0^{\circ}$ ply is positioned further from adhesive 
interface. By comparing AERO (quasi-isotropic symmetric) laminates with QIQH laminates, they excluded local effect and found that joint strength increases as $0^{\circ}$ ply are closer to laminate surfaces.

The literature review gives two clear conclusions. First of all, $0^{\circ}$ ply is the most important part of a laminate in the single lap joint. The final failure mode is definitely delamination between $0 / \theta$ wherever cracking initiation happens. The $0 / \theta$ delamination initiation means that the joint has reached its maximum loading. Secondly, position of $0^{\circ}$ ply affects joint strength both locally and globally. This article is trying to prove the above conclusions via finite element method. A new research method that composing single lap joint using two laminates that have different stacking sequences will be adopted.

\section{Finite Element Modeling}

Composite laminates used in this article are made of CYCOM X850-35-12K prepreg. They are bonded together as a single lap joint by adhesive J-116B. This configuration has high quality in bondline so damage usually happens in laminates during tension loading. Designing of specimen is referred to standard ASTM D3165. The lap length is set to $50 \mathrm{~mm}$. Its geometric appearance and mechanical properties are shown in Figure 1, Table 1 and Table 2.

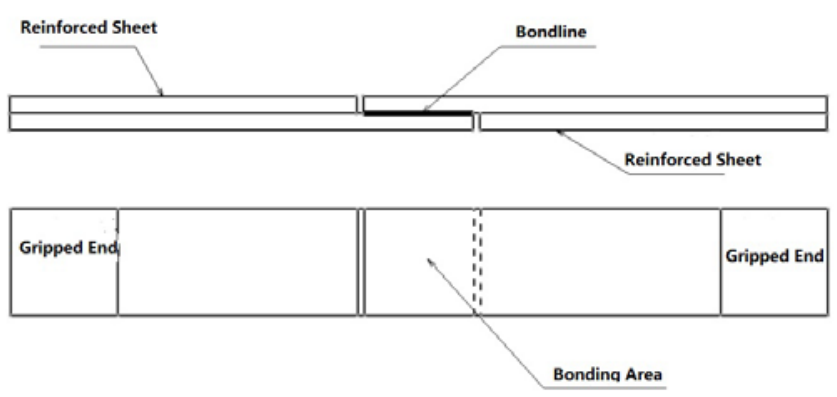

Fig. 1 Geometric Design of Single Lap Joint

Table 1 Mechanical Properties of Lamina

\begin{tabular}{|c|c|c|c|c|c|c|c|c|c|}
\hline Stiffness & $E_{1}$ & $E_{2}$ & $E_{3}$ & $v_{12}$ & $v_{13}$ & $v_{23}$ & $\mathrm{G}_{12}$ & $\mathrm{G}_{13}$ & $\mathrm{G}_{23}$ \\
\hline Gpa & 168.5 & 10.3 & 10.3 & 0.33 & 0.33 & 0.30 & 6.21 & 6.21 & 3.00 \\
\hline Strength & $\mathrm{X}_{\mathrm{t}}$ & $X_{c}$ & $\mathrm{Y}_{\mathrm{t}}$ & $\mathrm{Y}_{\mathrm{C}}$ & $\mathrm{Z}_{\mathrm{t}}$ & $\mathrm{Z}_{\mathrm{c}}$ & $\mathrm{S}_{12}$ & $\mathrm{~S}_{13}$ & $\mathrm{~S}_{23}$ \\
\hline Мра & 2785.6 & 1071.3 & 74.8 & 332.9 & 80.0 & 150.0 & 120.9 & 120.9 & 120.9 \\
\hline
\end{tabular}

Table 2 Mechanical Properties of Adhesive

\begin{tabular}{cccccc}
\hline $\mathrm{E}$ & $\mathrm{G}$ & $v$ & $\mathrm{~S}_{\text {mises }}$ & $\mathrm{G}_{\mathrm{D}}$ & $\mathrm{G}_{\mathrm{S}}$ \\
\hline $2.0 \mathrm{Gpa}$ & $0.77 \mathrm{Gpa}$ & 0.3 & $40.5 \mathrm{Mpa}$ & $0.5 \mathrm{~N} / \mathrm{mm}$ & $0.5 \mathrm{~N} / \mathrm{mm}$ \\
\hline
\end{tabular}

The single lap joint is composed of two quasi-isotropic symmetric laminates. In each laminates there are $0^{\circ}, \pm 45^{\circ}, 90^{\circ}$ oriented plies. Three types of laminates are made using these four differently oriented plies, they are listed in Table 3 . The plies in bold are the surface layers which contact with adhesive interface. For the reason of avoiding 0/90 interface and the situation that $90^{\circ}$ ply being the surface layer, $0^{\circ}$ ply cannot be of the third layer from bondline.

Table 3 Stacking Sequence of Laminates

\begin{tabular}{ccc}
\hline $\begin{array}{c}0^{\circ} \text { ply is the } 4^{\text {th }} \text { layer from } \\
\text { bondline }\end{array}$ & $\begin{array}{c}0^{\circ} \text { ply is the } 2^{\text {nd }} \text { layer from } \\
\text { bondline }\end{array}$ & $\begin{array}{c}0^{\circ} \text { ply is the surface layer } \\
\text { from bondline }\end{array}$ \\
\hline$[\mathbf{4 5} / 90 /-45 / 0]_{\mathrm{S}}$ & {$[\mathbf{4 5} / 0 /-45 / 90]_{\mathrm{S}}$} & {$[\mathbf{0} /-45 / 90 / 45]_{\mathrm{S}}$} \\
\hline
\end{tabular}

Among the laminates described above, [0/-45/90/45]s has the largest bending stiffness while [45/90/-45/0]s has the smallest. The joint bending stiffness is limited by the largest bending stiffness of the two laminates. So if [0/-45/90/45]s is bonded with the other two types, the joints will have the 
same bending stiffness as [0/-45/90/45]s. By this way the global effect is eliminated and local effect is the only factor that affects joint strength. Table 4 gives the single lap joints that are to be studied.

Table 4 Matches of Laminates with Different Stacking Sequence

\begin{tabular}{cc}
\hline No. & Laminates Matches \\
\hline 1 & {$[\mathbf{4 5} / 0 /-45 / 90]_{\mathrm{s}} \times 2$} \\
2 & {$[\mathbf{0} /-45 / 90 / 45]_{\mathrm{s}} \times 2$} \\
3 & {$[\mathbf{4 5} / 90 /-45 / 0]_{\mathrm{s}}+[\mathbf{4 5} / 0 /-45 / 90]_{\mathrm{s}}$} \\
4 & {$[\mathbf{4 5} / 0 /-45 / 90]_{\mathrm{s}}+[\mathbf{0} /-45 / 90 / 45]_{\mathrm{s}}$} \\
5 & {$[\mathbf{0} /-45 / 90 / 45]_{\mathrm{s}}+[\mathbf{4 5} / 90 /-45 / 0]_{\mathrm{s}}$} \\
\hline
\end{tabular}

The joint include composite and adhesive materials, as well as two types of interface, the interlaminar interface and adhesive interface. In the FEM model the two types of interfaces are represented by cohesive elements. Figure 2 illustrates modeling details.

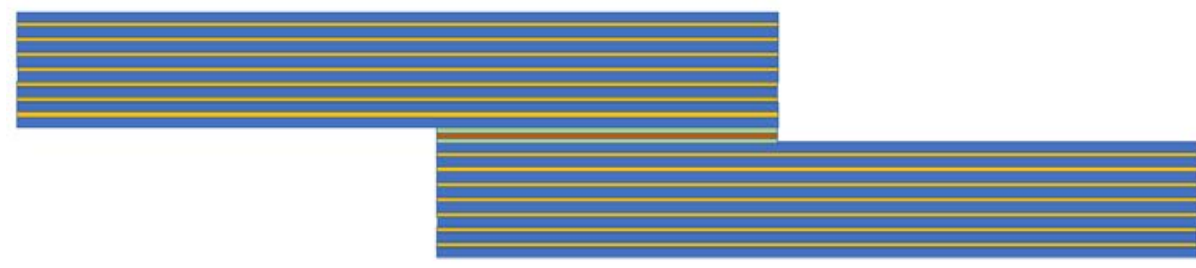

Composite

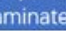

Adhesive

Fig. 2 Finite Element Modeling Details

\section{Result and Analysis}

Table 5 Computing Result of Finite Element

\begin{tabular}{ccc}
\hline No. & Laminates matches & Failure load/kN \\
\hline 1 & {$[\mathbf{4 5} / 0 /-45 / 90]_{\mathrm{s}} \times 2$} & 13.206 \\
2 & {$[\mathbf{0} /-45 / 90 / 45]_{\mathrm{s}} \times 2$} & 13.835 \\
3 & {$[\mathbf{4 5} / 90 /-45 / 0]_{\mathrm{s}}+[\mathbf{4 5} / 0 /-45 / 90]_{\mathrm{s}}$} & 13.240 \\
4 & {$[\mathbf{4 5} / 0 /-45 / 90]_{\mathrm{s}}+[\mathbf{0} /-45 / 90 / 45]_{\mathrm{s}}$} & 13.017 \\
5 & {$[\mathbf{0} /-45 / 90 / 45]_{\mathrm{s}}+[\mathbf{4 5} / 90 /-45 / 0]_{\mathrm{s}}$} & 13.345 \\
\hline
\end{tabular}

As shown in Table 5, No.2, 4, 5 specimens have one same substrate as [0/-45/90/45]s, meaning that they are consistent in bending stiffness. No.2 has the largest failure load while No.4 has the smallest. In other words, $0^{\circ}$ ply being located as the surface layer from bondline makes the joint stronger while as the 2nd layer makes the joint weaker. No.1 and No.3 specimens have one same substrate as [45/0/-45/90]s. Their bending stiffness are also consistent. No.3 has a larger failure load than No.1 though the difference is quite small. Comparison of failure load of all the five specimens is demonstrated in Figure 3.

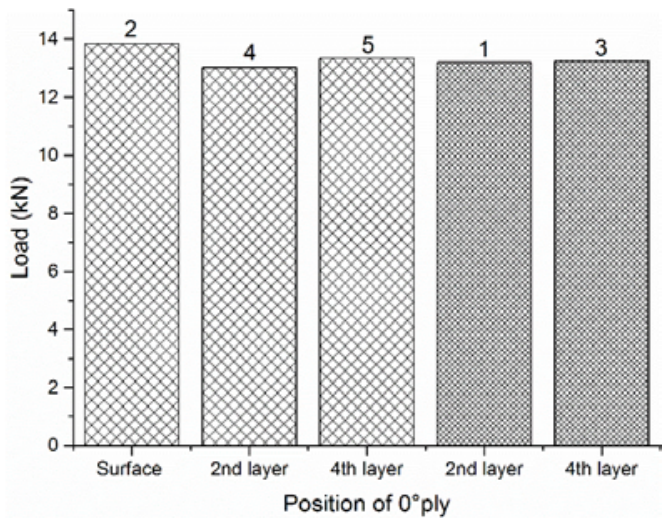

Fig. 3 Influence of 0 Ply Position on Joint Failure Load 
Finite Element outputs provide visualization of failure mode. As stated in introduction, $0 / \theta$ delamination is the basic reason of load decline. This conclusion is proved in the FE analysis. Figure 4 to 8 show delamination of each damaged laminate. An 8-ply laminate has 7 interlaminar interfaces. The delamination status is controlled by an output variable called SDEG, which varies from 0 to 1. The value of 1 means delamination happening, and the corresponding area turns red from blue. In each Figure, the upper part is stress distribution inside the laminate during tension loading. It is obvious that $0^{\circ}$ plies have the highest stress. The left part shows delamination initiation around the time when tension load reaches maximum value. The right part shows delamination growth after a period time of maximum tension load.

Figure 4 reflects delamination status of No.2 specimen. As tension load reaches maximum, delamination mainly initiates and grows in 0/45 interface. Other interfaces also have very small delamination area. Figure 5 reflects delamination status of No.4 specimen. In this joint only laminate with [45/0/-45/90]s stacking sequence is damaged. Before delamination there is matrix damage in each layer except $0^{\circ}$. Delamination initiates and grows in $45 / 0$ and $0 /-45$ interface. Very little delamination occurs in other interfaces. Figure 6 reflects delamination status of No.5 specimen. Similar to No.4, delamination mainly occurs in -45/0 interface. Figure 7 and 8 shows delamination status of No. 1 and 3 specimens. In both cases delamination occurs and propagates in $0 / \theta$ interfaces, quite similar to No.5 and 6 specimens.

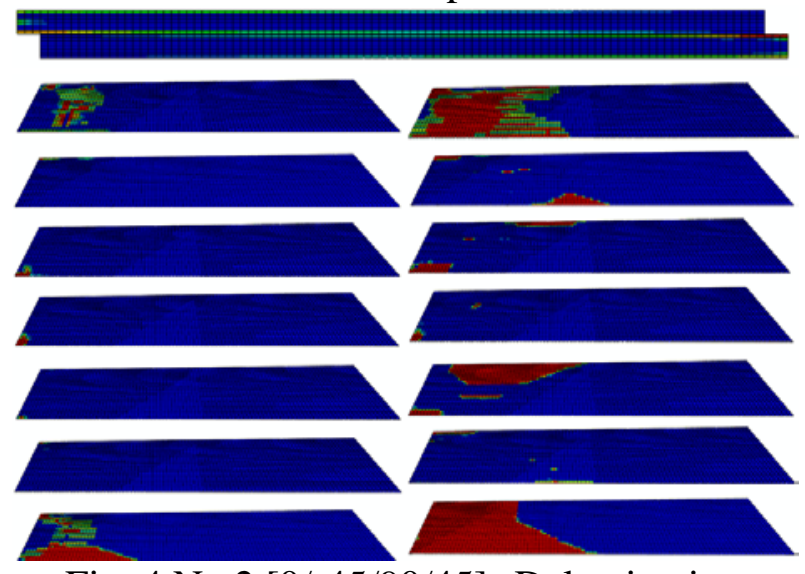

Fig. 4 No.2 [0/-45/90/45]s Delamination

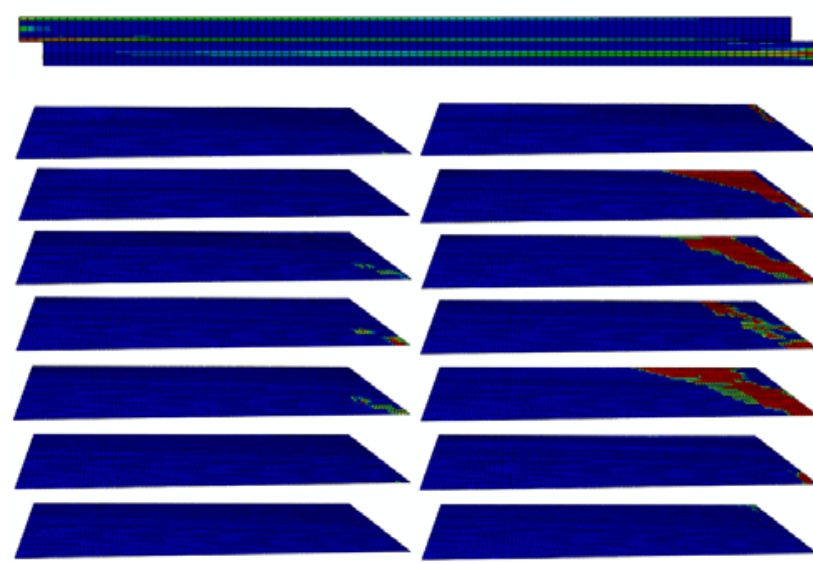

Figure 6. No.5 [45/90/-45/0]s Delamination

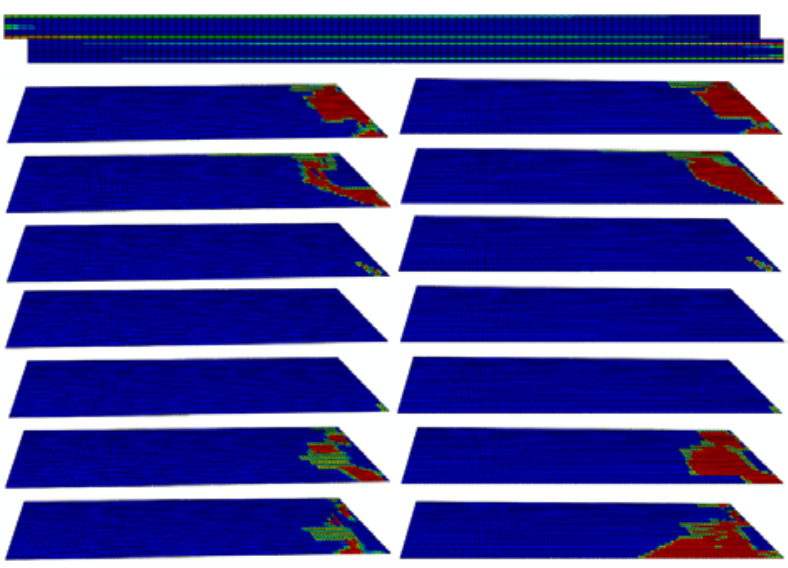

Figure 5 No.4 [45/0/-45/90]s Delamination

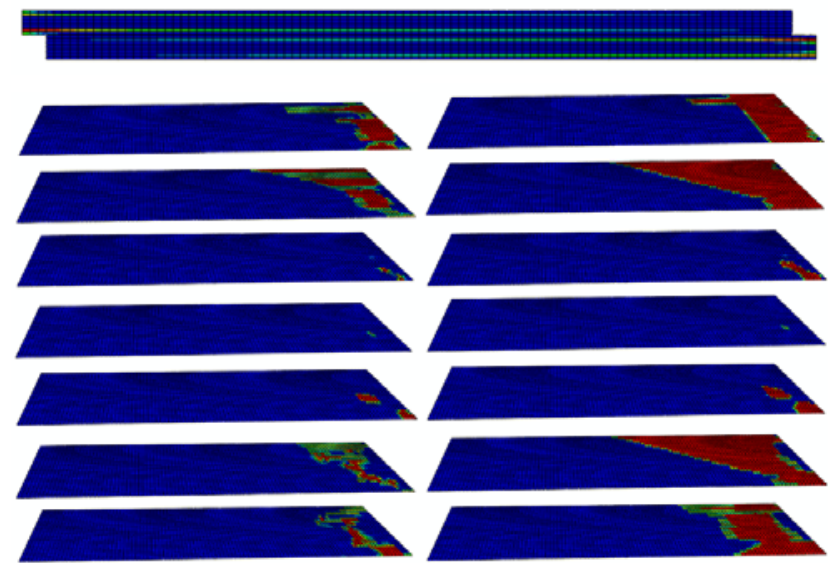

Figure 7. No.1 [45/0/-45/90]s Delamination 


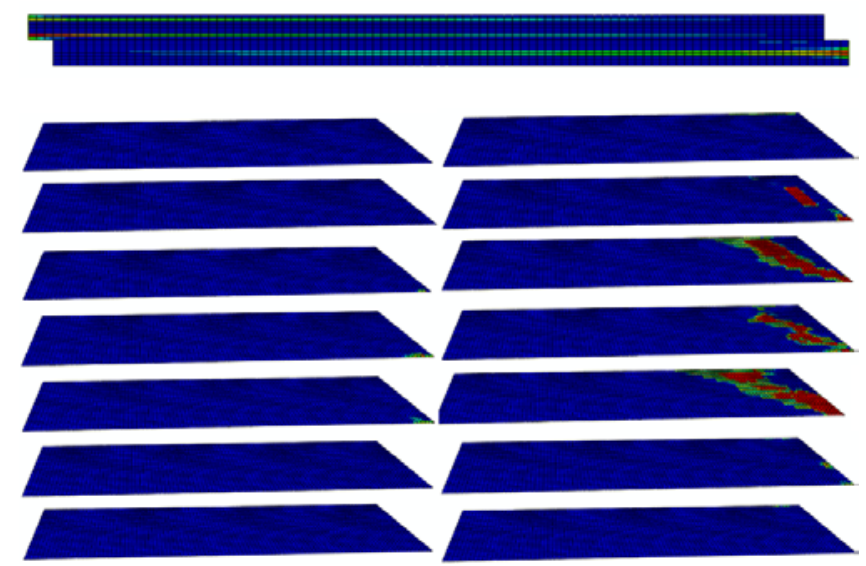

Figure 8. No.3 [45/90/-45/0]s Delamination

\section{Conclusions}

The strength of single lap joint composed of quasi-isotropic symmetric laminates is deeply influenced by $0^{\circ}$ plies. During tension loading, $0^{\circ}$ plies have the largest modulus in tension direction, bearing the highest stress. $0 / \theta$ delamination is the direct reason of joint failure, corresponding to maximum tension load. Delamination grows mainly along the $0 / \theta$ interface after failure.

The difference of stacking sequence of the two laminates within one single lap joint has influence on joint strength. However, the influence is not significant. Joints that contain a [45/0/-45/90]s laminate usually have lower strength, meaning that $0^{\circ}$ ply being the 2nd layer takes negative effect. When $0^{\circ}$ ply is the surface layer, damage initiation may have a higher threshold. When it is the 4th layer , damage growth will experience a more complex route before it reaches $0^{\circ} \mathrm{ply}$, postponing $0 / \theta$ delamination. Both of the two cases have positive effect on joint strength, but the $0^{\circ}$-surface configuration brings more benefits.

\section{References}

[1] Vinson J R. The Efficient Design of Adhesive Bonded Joints[J]. Journal of Adhesion, 1975, 7(3):175-193.

[2] Matthews F L, Tester T T. The influence of stacking sequence on the strength of bonded CFRP single lap joints[J]. International Journal of Adhesion \& Adhesives, 1985, 5(1):13-18.

[3] Kairouz K C, Matthews F L. Strength and failure modes of bonded single lap joints between cross-ply adherends[J]. Composites, 1993, 24(6):475-484.

[4] Meneghetti G, Quaresimin M, Ricotta M. Influence of the interface ply orientation on the fatigue behaviour of bonded joints in composite materials[J]. International Journal of Fatigue, 2010, 32(1):82-93.

[5] Satthumnuwong Purimpat, Rousseau Jérôme, Aivazzadeh Shahram. Effect of fiber angle orientation on a laminated composite single-lap adhesive joint[J]. Advanced Composite Materials, 2013, 22(3):139-149.

[6] Johnson W S, Mall S. Influence of interface ply orientation on fatigue damage of adhesively bonded composite joints[J]. Journal of Composites Technology \& Research, 1986, 8(1):5.

[7] Apalak Z G, Apalak M K, Genc M S. Progressive Damage Modeling of an Adhesively Bonded Unidirectional Composite Single-lap Joint in Tension at the Mesoscale Level[J]. Journal of Thermoplastic Composite Materials, 2006, 19(19):671-702. 